\title{
BATTLING AGAINST INTERFAITH RELATIONS IN ISRAEL: RELIGION, THERAPY, AND SOCIAL SERVICES
}

\author{
Yohai Hakak \\ Brunel University
}

\begin{abstract}
One of the less studied aspects of the Israeli-Palestinian conflict is its demography. On the Jewish side, active steps are taken by the state to encourage Jewish immigration and Jewish births and discourage Jewish assimilation. As part of these efforts, the "problematic relationships" between Arab men and Jewish women from low socioeconomic background have become a high agenda item in public discussions in Israel during the last decade. I will examine here how the diagnostic category "girls at risk" and a therapeutic intervention employed by social services dealing with these couples helps maintaining the delicate balance between Jewish and democratic values. I will analyze these practices as a solution to a structural problem of the Jewish enclave in Israel.
\end{abstract}

In the last decade, Israeli media have repeatedly reported about cases of domestic violence in mixed Jewish-Arab couples, some of which have ended tragically, including the murder of one Jewish woman. ${ }^{1}$ Many TV programs, radio shows, and newspaper articles have profiled these relations, and almost always in very negative terms. Some reports are accompanied by filmed semi-military "rescue operations" of these women by the Jewish Ultra-Orthodox organization "Yad-Le'achim" (Hand to Our Brothers, in Hebrew, the author), which is exclusively dedicated to fighting Jewish assimilation. Members who are ex-soldiers, collaborating with the Israeli Defence Force (IDF) and Israeli police, enter into Palestinian territory and extract Jewish women and their children who have requested the organization's help. The organization also operates a hotline for girls and women considering or already involved in relationships with Arab men and offers support for their concerned family members. The hotline is manned by social workers who hold very negative views of such relationships, and the organization distributes much printed material including pamphlets and books and has an active Web site (http://www.yadlachimusa.org.il/). Of its many activities, its rescue operations receive much media attention because of the winning combination of "action" and "forbidden relationships." In particular, in areas where Jews and Arabs interact regularly, groups of concerned parents and members of the public have organized routine patrols in recent years, to tackle and minimize such "undesirable relationships." Such groups regularly visit public parks, malls, and streets where young people hang out and attempt to prevent Arab men from approaching Jewish girls and young women and to ensure that Jewish girls and women, if approached, will be less likely to respond positively. Local authorities' legislations, such as the laws prohibiting the congregation of nonresidents in residential areas after 23:00, are used especially against Arab men. ${ }^{2}$ In recent years, several marches took place in different cities in protest against these "foreign men" who "steal our daughters," and in a number of cases assaulted the Arab men implicated. The Israeli Knesset also contributed to this moral panic and held several special discussions in different forums on the issue, including two emergency meetings.

In a previous article, I analyzed the ways in which the Jewish women and the Arab men in these relationships are presented and how their behavior is explained (Hakak, under review). This article, based on the analysis of governmental documents, will examine the different attempts to prevent and dismantle such relationships once they have formed. Sources include the transcripts of a series of discussions that took place in the last decade in several Israeli Knesset parliamentary committees and the Knesset plenary assembly, and documents produced by a

Dr. Yohai Hakak, Department of Clinical Sciences, Brunel University.

Address correspondence to Yohai Hakak, Department of Clinical Sciences, Brunel University, London, Uxbridge, UB8 3PH, UK; Email: yohai.hakak@brunel.ac.uk 
variety of governmental agencies working with young people. I will analyze the main discursive practices used by those involved and divide the presentation into two.

The first section will analyze the different avenues of action considered by those opposing these relations, including the legal and educational, as well as their limitations. As I will show, it is far from simple to reconcile the commitment to democratic values with the commitment to Jewish values, including the prevention of assimilation. The psychological discourse and the diagnostic category "girls at risk" provide a way to maintain this difficult balance.

The second section will examine ways in which this diagnostic category is employed. I will argue that this topic exposes profound structural problems the Jewish enclave in Israel is facing, as well as some of its attempts to deal with them.

\section{ATTEMPTS TO PREVENT MIXED MARRIAGE IN A GLOBAL PERSPECTIVE}

Prohibitions on mixed marriage for people from different religions, races, classes, ethnicities, nationalities, and more have existed throughout human history. The literature on mixed race relations, and the attempts to prevent them, is especially rich in that period of American history following the abolition of slavery (Tucker, 2004). As several studies show, antimiscegenation laws do not merely reflect existing "racial knowledge" but establish it and go far to shape social borders and identities (Connolly, 2009; Sohoni, 2007).

Many studies analyze the role of the state in restricting mixed marriages (Semafumu, 1998; Shibata, 1998). Others explore the creation and implementation of laws designed to prevent or restrict such marriages, as well as the work of the civil servants entrusted with implementing them through registering married couples (Breger, 1998). Several studies make it clear that the legal system is the first and the main barrier for mixed marriages (Breger, 1998; Hoewe \& Zeldes, 2012; Lombardo, 1987; Pascoe, 1996; Sohoni, 2007).

As in many societies, women's bodies are equated with national honor, most react more strongly to cases in which "our girls" are "taken" by "other men" than to cases when "our men" develop relations with "other women." Many studies describe with striking similarities how "our girls," the "other men," and "their children" are portrayed in these different contexts (Bland, 2005; Cornwell, 1996; Das, 1995; Foeman \& Nance, 1999; Ladd-Taylor, 2001; Triger, 2009).

After the legal system, counseling and psychology-related professions (Rose, 1996) are the second line of defense against mixed marriage. Celello (2010), who analyzes marriage counseling texts written during the 1950s in the United States, analyzes the different arguments used to convince mainly White girls to avoid such marriages. As Celello explains, "experts highlighted the alleged poor mental health of those men and women who desired to marry outside of their race or faith and suggested that those who went through with such unions 'would suffer severe social consequences" (Celello, 2010, 43).

\section{JEWISH-ARAB MIXED RELATIONS IN ISRAEL: THE CONTEXT}

As a minority religion, Judaism is very concerned about assimilation. To minimize assimilation, a high level of well-planned segregation between Jews and Arabs is maintained in Israel. A continuous Israeli-Arab conflict justifies this segregation and maintains the status of fellow Arab citizens as part of the enemy camp. State-funded education offers separate school systems for each group. While Hebrew plays a central role in Arab schools, Arabic has very little presence in Jewish schools, and if taught at all, it is classic Arabic, not the spoken Arabic used in everyday life. Most Arabs and Jews live in Arab- or Jewish-only cities, towns, or villages, and the number of mixed cities, towns, or villages is small. In those that are mixed, Jews and Arabs live in different areas and rarely meet. After finishing high school, most Israeli Jews are recruited to the IDF. Muslims are exempted based on the assumption that they might pose a security threat. During their army service, Jewish Israeli youth might meet Arabs, but these interactions only intensify the segregation between these populations. In civilian life, the Israeli labor market is also highly segregated.

All of these factors minimize the interaction between both the groups, especially between young people. For most Israelis, the option of crossing these lines of segregation through a romantic relationship is inconceivable. 
Many of those objecting to interfaith marriage are religious people for whom such relations are a grave sin. Despite this, the arguments these opponents make are rarely religious because they are mainly addressed to nonreligious Jews. A good example for the gap between the internal motivation and the external justification is the rhetoric used by the Haredi (Jewish Ultra-Orthodox) NGO Yad-Le'achim. While affiliated with Ultra-Orthodoxy, its official rhetoric rarely mentions its religious motivation as a reason for avoiding such relations. Instead, it emphasizes a wide variety of other reasons.

One of the crucial social changes that seems responsible for the rise in the number of interfaith relations is the waves of immigration from Ethiopia (since 1984) and the former USSR (since 1989). These waves brought over 1 million immigrants to Israel based on the Law of Return. ${ }^{3}$ Of these, about 300,000 immigrants, who were regarded as having "Jewish ancestry," and were therefore eligible to immigrate, were at the same time considered as not "sufficiently Jewish" according to Orthodox Judaism. Consequently, this group of immigrants is unable to marry other Jews through the religious court system - the only available rout for marriage - and therefore suffers extreme marginality.

According to the Population Registry, Ministry of Interior, about 5\% (about 100,000) of married couples in Israel are mixed (Mai-Ami, 2008). In most of these couples, the non-Jewish partner was born to a Jewish father or grandfather who married a non-Jewish wife. These couples were married outside of Israel.

Another key aspect is the very different approach to these relations based on the ethnicity and social class of the individuals involved. There are currently a few but well-known cases of mostly Ashkenazi middle-class women, who usually work in the arts or media and have Arab male partners such as Dana Modan and Kais Nashef or Yael Ronen and Yousef Sweid. The public debate does not relate to these successful women, and their self-determination is not questioned. A totally different response is experienced by women from lower socioeconomic background, many of them were immigrants.

\section{JEWISH-ARAB MIXED RELATIONS IN ISRAEL: THE LITERATURE}

The literature on Jewish-Arab mixed relations is relatively limited but includes several important contributions. Triger's (2009) extensive article reviews the legal and cultural aspects of mixedfaith marriage in Israel. Triger shows how the Israeli legal system, caught between its commitments to democratic and Jewish values, does not directly prohibit interfaith marriage but simply assigns exclusivity over the issue to religious law and religious courts which of course oppose such marriages. At the same time, no procedures or mechanisms for conducting civil marriage exist. As Triger rightly points out, the fact that the state does not prohibit such marriages directly does not decrease the prohibition's validity "but only makes it invisible and thus renders it absent from public discourse" (Triger, 2009, 481).

Using qualitative methods, a few studies have explored the actual relationships between Arab men and Jewish women (Abu-Rayya, 2000; Cohen-Golani, 2011; Racin \& Dein, 2010; Roer-Strier \& Ben-Ezra, 2006) or Arab-Israeli men and Western Christian women (Abu-Rayya, 2007; RoerStrier \& Ben-Ezra, 2006). These studies enrich our understandings of the experiences of these couples and the difficulties they faced, including society's responses. A critical examination of the studies conducted by Israeli-Jewish authors reveals the sensitivity of the topic and their own struggle with it. Racin and Dein (2010), for example, consider their main task to "assess the women's motivations for entering these relationships..." Such a task might give the impression that the authors see such a decision as questionable. Cohen-Golani (Cohen-Golani, 2011) explores the experiences of Jewish women in interfaith relationships, but the fact that none of her interviewees was still in such relations while interviewed contributes to a very negative theme running through all their descriptions. Using quantitative methods such as questionnaires, Keysari (2000) focuses his study on girls from a closed institution for 14- to 21-year-old girls, Tzofia. Girls are admitted by a court order, and according to Keysari $(2000,2)$, "educators and social workers that treat these teenagers report that many of them have/had romantic relationships with boys from the Arab minority community." Keysari sees an explanation of these relations in the affinity between these two marginal groups: Mizrahi (including immigrants from the Muslim republics of the former USSR), Jewish 
teenage girls and women from low socioeconomic backgrounds, and Arab teenage boys and men. He also highlights the extreme cultural affinity enabling these relations between these two groups, including their shared patriarchal family structures. Keysari is interested in the psychological reasons that make some Jewish girls more likely to develop such relations than others, and focuses on two variables: the girls' attachment style and their tendency to take risks. Based on a sample of 30 girls who had experienced such interfaith relations and a similar sized control group of girls who had not, Keysari confirms his hypotheses that girls with an Arab partner are more likely to have an avoiding or anxious attachment style and are more likely to take risks. This study pathologizes these young girls and explains their attraction to Arab partners as resulting from their psychological dysfunctions, ${ }^{4}$ but surprisingly and presumably unintentionally, their attraction to Arab men is also portrayed as a very logical and even as a healthy choice considering their "pathologies" (Keysari, 2000, 26-27):

"These girls are characterized by a dysfunctional attachment style and have a need in a relationship that will include many positive external cues which will help them overcome their (inherent, the author) lack of trust in their partner. In a relationship with a minority (euphemism for Arab, the author) partner, they feel held and contained as a result of cultural or personality characteristics of their partners... Because they were deprived of warmth and reassurance their need for a supportive and containing partner increases... these girls choose minority men as partners since they lavish them with love and warmth, are a very strong base of support, buy them expensive gifts and even protect them physically... the girls feel protected and supported even if their surrounding (family, welfare and education officials) constantly give them the message that they are at risk, lost and confused, and that the relationship with these minority men isn't safe and should be broken." 5

So why are these relations being regarded risky? Arab men are often presented as deceitful, pretending to be warm and generous at the early stages to lure the young woman and marry her. Once married, the rules of the game change, especially if the women move to live in an Arab area. Then, she is likely to be demoted to the role of a servant, abused, and beaten if she does not comply (Hakak, under review). According to Keysari, these relations are risky because the girls at risk being cast out and even physically attacked by their own family members (p. 4). A variation on this explanation is given by Cahan-Stravchinsky et al. $(2005,45)$ who bring the arguments raised by social workers working with girls at risk stating that, "in many cases the girls link up with Palestinians from the (occupied) territories and moving in these territories in the current political situation might danger the girls' lives. When these are Israeli Arabs, in most cases the girls link up with negative elements in this society. These relations start as relations of acceptance but end up as abusive relations that worsen the girls' situation."

Of special importance is the study by Razi (2009) in which she analyzed archived materials documenting the activities of social welfare services in Tel Aviv during the 1930s and 1940s and their interventions in similar situations. Just like contemporary conditions, the years examined by Razi are also characterized by big waves of immigration. One of the issues that social services were highly concerned about was the relationships Jewish girls from low socioeconomic background, usually Mizrahi, developed with Arabs. "These acts were perceived as the most dangerous expression of crossing religious and national borders, and as a sign of the ethnic proximity between Mizrahi Jews and Arabs, which in itself threatened the national, ethnic and geographical separation between Jews and Arabs" (Razi, 2009, 250). On some occasions, they were looked at in a more sympathetic light, as victims of vicious men. Some of these girls were incarcerated in closed institutions for girls, to "protect" them from these relationships. In other cases, according to Razi, social services in collaboration with the religious administration supported the marriage of minor underaged girls, arranged by their families in an attempt to "save" them from an Arab they were involved with (Razi, 2009, 251). Despite the many differences between the social services' personnel that were very secular, and the rabbinate, these two social institutions found an ideological common ground: the attempt to preserve and maintain the borders of the national collective. The ethnic and class marginality of these young women and girls made them an especially easy target for the intervention of social services and the rabbinic administration. 
Key discourse that is used in the case which I will analyze is that of risk. I will use Mary Douglas' cultural theory and her contribution to the understanding of risk. Douglas is joined by many other scholars who argue that risk "is not a static, objective phenomenon, but is constantly constructed and negotiated as part of the network of social interaction and the formation of meaning" (Lopton, 1999, 29). Douglas's contribution goes far beyond this point and provides a fascinating typology of several key social formations, the structural problems they face, and the way in which each defines risk as a result. "Most institutions tend to solve some of their organizational problems through public allocation of blame. Naturally, these problems and the blaming procedures vary according to the kind of organizations" (Douglas, 1985, 56). One of the three sociocultural formations identified by Douglas and is especially relevant to this article is the enclave, which is a community that chooses to separate itself from its surrounding society. The main problem of the enclave is the voluntary nature of its membership, and therefore, it is constantly under the threat of their possible defection. As the enclave cannot force its members to stay, it has to develop mechanisms to prevent their defection. The Jewish people as a minority religious enclave group that survived in exile for 2000 years have developed a wide range of such mechanisms to prevent the defection of its members. The establishment of the State of Israel as a Jewish and democratic state ensured their preservation of many of these mechanisms. My analysis of the data will illustrate one such key mechanism.

\section{Jewish and Democratic: Preventing Mixed Relations while Maintaining the Existing Balance of the Law}

Starting from the early 2000s until 2011, the "problematic" relations between Jewish women and Arab men were mentioned, by the way, during several Knesset parliamentary committees. The main focus of discussion was usually on other issues, such as prostitution among youth or "locating girls who ran away from closed institutions," both debated by the Committee on Children's Rights. As will be described, only in recent years did more direct discussions about this topic take place.

In 2006, the State Comptroller published his report about the treatment of girls at risk by different state agencies in a sample of four local municipalities (Lod, Afula, Kiryat Gat, and BneiBrak). The report describes the relationships between the different agencies involved, as well as the procedures used and the quality of the services given. One of its last sections deals with "girls at risk who befriended adults." It uses very cautious and abstract language and mentions that in 2004 and 2005, 29 girls from Kiryat gat and 25 girls from Afula had relations with "adults" from "the margins of society." "More than half of these girls spent from one week to eight months in the houses of these adults... some of the girls were involved in criminal activity such as drug dealing or prostitution and also used drugs." This report was at the center of discussion of the Knesset Parliamentary Committee for Internal Affairs, held on 29 May 2007, a few months after the report's publication. During the meeting, Menachem Wagshal, Deputy Director General of the Ministry of Welfare and Social Services, explained:

About the issues of 'befriending adults' - we had a thorough discussion, also with our legal advisors. No one speaks clearly on this issue (though, the author)... everyone knows what is meant. I don't think that this is an issue I would like to relate to here as also according to our legal advisors there is no law in the State of Israel. . . that says when a girl can't befriend an adult. . Nobody will be able to say that in 'befriending adults' you will be able to say from which (ethnic or national, the author) origin you can and can't befriend an adult. This is why it is so complicated.

These issues were reiterated later during that meeting by Mr. Yoseph Fond, a Department Deputy Manager at the State Comptroller: "We definitely didn't write even one word in the report that relates to religion or nationality. We don't deal with religion and nationality and didn't go into who these adults were. We are talking about people at the margins of society that pull the girls in a negative direction." A last reference to the issue during this committee meeting was made by Ron Gilboa, Head of Welfare Services at Lod's municipality, which was also examined in the report. The city of Lod has a very mixed population of Jews and Arabs living together and a relatively high number of such mixed couples. "Most of our funds go to three safe houses for girls at risk," 
explained Gilboa. "We were required to deal with this issue due to the problem that was explained here of our girls befriending problematic adults" (the emphasis is mine, the author). Gilboa then explains that his municipality made a special effort to collect much more funds than expected by the Ministry of Welfare for spending on services for these girls "as this issue is in our soul." These short quotes evidence the legal difficulties that are part of the commitment not to discriminate based on religion or nationality on the one hand, but on the other, they evidence the wish to prevent these relations that are deemed problematic.

Reviewing the discussions about this issue, held in the different parliamentary committees and as part of the Knesset plenary discussions, indicates a shift in the way the topic is presented in more recent years and the place it occupies. In February 8, 2011, and as part of "The Jewish Identity Day" at the Knesset, the issue was put forward for the first time as the main issue for discussion in the Committee on the Status of Women. A few months later, it was the reason for a special emergency meeting of the committee on Immigration, Absorption and Jewish Diaspora (held on December 8,2011 ) to discuss the phenomenon of "kidnapping of new-immigrant teen girls by members of minority groups" due to allegedly numerous cases. Just a few months later (May 1, 2012), it was again the reason for a special meeting of the Committee on Children's Rights, due to the multiplicity of such "problematic" relations in the city of Lod. It is clear that a growing number of parliamentary members took this issue "under their wings" and are committed to it and that they do not see any problem in the value base it represents and its possible tension with more liberal conceptions of individual choice.

\section{The Legal Path: Criminalizing Arab Men}

In many of the parliamentary meetings, there is a discussion about how to respond to advances by Arab men. Many girls describe these in positive terms, but professionals and others involved are much more skeptical and dismissive. They see these relations as abusive, the advances as criminal, and support punishment. An example is the emergency meeting of the Parliamentary Committee on Immigration, Absorption and Jewish Diaspora held on December 8, 2011, to discuss the phenomenon of "kidnapping of new-immigrant teen girls by members of minority groups." Member of Knesset (MK) Danny Danon, the committee's chair, opened the meeting declaring:

This is an emergency meeting. We were all exposed to very frightening evidence of the troubling rise in the number of cases of young women from low socio-economic background that are simply being kidnapped... I found out that there are cases in Israel of 2011 that girls are being kidnapped mid day in Kiryat Malachi, Arad, Beer-Sheva, Naharia, and that (men from) minority groups are simply forcing girls into cars... It is important to mention that most of the cases aren't cases of physical kidnapping but cases are such in which a romantic relationship is being developed, based on an economic need and luring of these girls, most of them new immigrants.

Later on in the meeting, Member of Knesset (MK) Danon invited Alina Zanani, the Head of the Social Work Team at the Yad-Le'achim organization, to share with the committee the information she has. Zanani said:

As we see it, kidnapping is an extreme case of a widely spread phenomenon in Israel that we deal with daily. We have over 1000 cases reported to us every year. . . and this phenomenon is growing. We are talking about a system of, as you called it - temptation. It starts with a temptation but these relationships turn to be ones of abuse, hurt and coercion.

The fact that Yad-Le'achim is a right-wing Haredi (Jewish Ultra-Orthodox) organization whose sole mission is fighting Jewish assimilation did not bother most committee members, or lead them to question their data or their interpretation of it. Shortly after his opening declaration, MK Danon asked the representative of Israeli Police, inspector Rachel Gribben, to respond to the data. The inspector's response was clear: “the police aren't familiar with such a phenomenon... we have had very few cases that were examined which can be described in a similar way to your description... but we are not familiar with such a phenomenon." This response raised an outcry from the only center-left delegate who took part in the meeting, MK Daniel Ben-Simon from the Labor 
party who left it after several minutes in protest. Other committee members criticized the police for not being aware of reality. Following the angry response of MK Ben Simon and the police delegate, some of the participants tried to better explain what they think is happening. Ben-Tzion Gupshtein, the Head of Lehava (a religious NGO dedicated to preventing interfaith relations), said:

"Just like we have a law that says that sex with a minor, ${ }^{6}$ even if they are willing, is forbidden, the same is needed here. The moment they 'buy' the girl with (a can of) coke, pizza, 500 shekels or a mobile phone and she is a minor - this is kidnapping. Indeed they don't take her by force, and you will ask her - she's fine... 'He gives me, why shouldn't I use him...' and when the family calls the police and the police calls the girl, the girl says 'why not? I love him'."

I suggest one should understand these arguments as part of an attempt—unsuccessful so far-to address this issue legally by criminalizing Arab men. Not less important was the fact that despite the police response, right-wing newspapers and media reported the following day with big headlines about 1000 cases of kidnapping and the temptation of minor girls by men from minority groups. This event is just one of the peaks in a successful campaign to create a moral and sexual panic (the author, under review). As this state of alarm increases, so do the chances that other "more reactive mechanisms of surveillance, regulation, discipline and punishment will be employed" (Herdt, 2009, 1). This moral-sexual panic taps into deeply embedded Jewish fears of those outside the enclave. Emphasizing the sense of danger and risk emanating from "the outside" is one of the key mechanisms that enclave communities employ to prevent the defection of their members, which is key to this article.

But even if this moral/sexual panic leads to further attempts to address this issue legally, it will not be simple, as Dr. Zvi Zameret, the chairman of the ministry's pedagogical secretariat, explained during the Committee on Women's Rights:

I want to emphasize something we all know but not always aware of. Circumcision is one of the more common practices in Israeli society today, even among those who are not considered as Jewish according to the Halacha. We should ask ourselves why. Among other reasons it is because there is no law, no coercion on this issue but a routed normative consciousness, and I want to worn very much from legislation that might alienate people.

Zameret is rightfully concerned that, as in the case of circumcision, if interfaith marriage will be presented as forbidden through legislation, or by education or any other mean, it will alienate Jews and be counterproductive. This is a structural problem typical to an enclave and "an attempt to impose penalties will merely make the membership melt away even faster" (Douglas, 1992, 138). The fact that such potential legislation will violate basic human rights is not mentioned here as an argument at all, although it is mentioned in other discussions where the introduction of new "educational" programs into state schools is considered. ${ }^{7}$ For all of these reasons, other less discriminatory laws including laws banning gatherings after a certain hour in the evening, or banning making of noise, are preferred. Even if these laws themselves are neutral, they are implemented in a discriminatory fashion, in this case against Arab men.

\section{The Psych-Professions Path: Diagnosing Girls "at Risk"}

As Israel aspires to be both Jewish and democratic, it remains committed in principle to the individual's right to decide on the nationality and religion of one's partner. This is where the psychological discourse becomes especially useful and why social workers, psychologists, and other representatives of the "psych"-professions (Rose, 1996) are asked to intervene.

I mentioned earlier the 2006 State Comptroller's report about the treatment of girls at risk by different state agencies and its reference to girls who befriended adults from national minorities. As part of this investigation, the report quotes the Head of the Department of Girls at Risk in Kiryat Gat municipality who explained the reasons that motivate girls to look for the company of these adults: "low self-esteem, lack of warmth and rejection by the family unit, parents out of the house due to long working days." Without clearly stating it, the Head implies that these relationships are the outcome of the parental neglect, rejection, and abuse experienced by these girls. These 
arguments were repeated in many recent parliamentary committees dealing with the topic. This is how Alina Zanani, the Head of the Social Work Team at the Yad-Le'achim organization, described these girls during a meeting of the Committee on the Status of Woman which took place as part of the Jewish Identity Day held in the Knesset on February 8, 2001:

As part of the therapy the girls go through we check thoroughly what led the girl to such a relationship. In most cases we find out that these girls had very difficult backgrounds of deprivation, sexual abuse, family traumas such as very difficult divorce of the parents, violent homes, severe financial difficulties, and the relationship with the Arab partner wasn't a result of the girls' choosing it, out of the an idyllic wish to unite the two nations. It is a relationship that is created out of the girl's attempt to run away (from her own reality, the author) and without all of the other factors of neglect and difficulty this relationship wouldn't have been created.

A few months later (on December 8, 2011) during the emergency meeting mentioned earlier due to the growing number of "kidnaps" of Jewish girls by men from national minority groups, Alina Zanani added the following details:

We are talking about weak women and girls who need protecting... Women and girls with weak personality, lacking judgment, with very limited ability to identify when they are being abused and resist it. . . and the role of the Immigration Committee to my mind is to identify these groups and built the appropriate services to inform and treat them.

According to Zanani, a Jewish girl will not date an Arab because she likes him for what he is. Choosing an Arab partner is just a symptom of her problem, a self-destructive attempt to run away from her problems. Not only are these girls unaware of their true motivations, but also their mental health problems damage their ability to identify when they are being abused, and therefore, they need to be safeguarded by the state. ${ }^{8}$

So far, I presented and analyzed the discourse of right-wing religious organizations and rightwing members of the Knesset. In the following sections, I will show that similar assumptions also guide the activities of main stream governmental social work agencies and the professionals working with young people.

\section{Treating "Harmful Relationships"}

During 2011, MK Zvulun Orlev took part in two Labor, Welfare and Health successive committee meetings (June 27 and November 28, 2011, protocols $500 \& 575$ ), both held in an attempt to form a draft law that will force the state to secure funding in every case that a special committee of social workers has decided that a child should be removed from their home. Usually, such a decision is made when the parents are abusive or there is a risk of neglect. But, in more than a few cases, such decisions are made when parents lose control of their child and professionals believe the young person would benefit from a more confined and protective environment. Orlev was signed on this draft law with his colleague MK Orly Levi-Abekasis as its initiators, and they were supported by several MK from the more center-left parties such as Ilan Gilon and Sheli Yehimovitch. MK from different parties believed that this would be a good way to overcome the current "quota system" that divides all social services across the country into geographical areas. Each has an allotted quota of funds for such cases as well as special places in closed institutions for youth. During both of the two successive meetings, the delegates of the Ministry of Welfare were very reserved about this draft law and tried to reject it as contrary to their attempts to develop community-oriented services.

Orlev and Levy-Abekasis' keen support of the draft law looks more questionable after reading the protocol of another parliamentary meeting that took place only a few months later. On May 1, 2012, Orlev, as its official chair, summoned the parliamentary Committee on Children's Rights for a special discussion on the "treatment of girls at risk in Lod." At the opening of the meeting, he explains that a month earlier he was approached by Mr Aharon Atias, the CEO of The Centre for Education and Society in Lod, who shared information with him about "very difficult situations of girls in very high levels of risk." Mr Atias informs the committee about a series of cases, all involving girls who developed relations with Arab men. ${ }^{9}$ The portrayals repeat the standard version: 
Arab men involved in criminal or semi-criminal behavior tempt naive young Jewish girls with money, jeans, and mobile phones. ". . .making them leave their homes and go to very dark places... where we see them with alcohol... using drugs. . sliding into prostitution." Mr Atias brought with him two of these girls' families (not including the girls in question). Family representatives were invited to speak, and clearly, they see any relationship with an Arab man as a problem in itself and disapprove of it. These stereotypical representations go unchallenged by any of the participants in the meeting. In an attempt to clarify his request, Mr Atias states:

I am here to give voice to the outcry for a long term treatment. . . to take the girls that are in this process... and rescue them; Girls who plead, take them to Zofia or Mesila (closed secure institutions) and give them solutions... I heard from our mayor, 250 women have converted to Islam in Lod and live in distress in all kinds of vaults. The situation is catastrophical, we can't continue like this.

Mr Atias' words are then followed by MK Orlev who reminds the participants of his draft law that will ensure such cases-where professionals believe a minor should be removed from their home and in some cases moved into a closed institution-will not be limited by the quota system. Representatives of the police and social services are also present. From all the speakers, it is clear that, contrary to the portrayals of these Jewish girls and women as weak and passive victims, the girls talk about very positive emotional involvement with their partners. The police delegate notes that in most cases these girls are unwilling to file a complaint or cooperate, and the same information is shared by others. It is also clear from the discussion that girls maintaining "problematic relationships" with Arab men are often sent to those closed "secure" institutions for long periods of "treatment and rehabilitation."

No doubt that some Jewish girls are at risk also due to their relationships with Arab men, but this is not due to them being Arab. But, "associating with minority groups" (a known euphemism for Arabs) has become officially acceptable as a "characteristic" or a "risk factor" of youth at risk, especially among professionals working with such youth. This is evidenced, for example, in the Ministry of Welfare's unit called the Youth Protection Authority, responsible for authorized outof-home therapy for teenagers for whom all previous treatment options have failed to bear fruit. On its official Web site ${ }^{10}$ are listed the "functional/performance characteristics" of the youth it works with: "lacking socialization habits; criminal behaviour; running away from home; vagrancy; associating with marginal groups (criminal gangs, minorities etc.) (emphasis is mine, the author); initial use of psychoactive substances to the point of addiction; dropping out of educational frameworks; suicide attempts; sexual irresponsibility; psychiatric behaviours."

The mention of 'associating with minority groups' (Bnei Miutim), which in Hebrew is a euphemism for Arabs, as a "characteristic" grouped together with "associating with criminal gangs," could not be more revealing. This "characteristic" translates in practice into a "risk factor" that professionals use to identify girls "at risk." The identification of these relations with "risk" is behind the growing number of governmental documents, surveys, and studies collecting evidence about them in which this group of women has become a social category on its own (NahshonGlick, Pliel-Trosman, \& Zinger, 2007; Kahan-Strawczynski, Yurovich, Konstantinov, \& Efrati, 2005, 45-46).

Counting and measuring the occurrence of these relations is easily translated into "intervention" or "treatment." Castel $(1991,288)$ sees the terminology of "risk factors" as a mode of surveillance based on "systematic predetection." These preventive policies no longer primarily address individuals but "factors, statistical correlations of heterogeneous elements. . . to be suspected, it is no longer necessary to manifest symptoms of dangerousness or abnormality, it is enough to display whatever characteristics the specialists responsible for the definition of preventative policy have constituted as risk factors" (Castel, 1991, 288). I would like to argue here that identifying relations with Arabs as a risk is both a mechanism that allows protecting the enclaves' borders and a result of the mentality created by this tendency and which tends to equate danger with the "outside."

An example of an intervention based on this discourse is found in a report published in 2007 by the Department for Social Services of the southern town Kiryat Malachi and also in an evaluation study by Noy-Rozov (2010, 56-57). It relates, among other activities, to a special intensive and long-term program for youth at risk and their families. The program included living in a "safe 
house," individual, group and family counseling and art therapy, a variety of psychological and psycho-didactic assessments, as well as very rich extracurricular activities. Forty Jewish teenage girls and 10 Jewish teenage boys took part in it during 2007. Page 19 of the report describes "the characteristics by which the boys and girls were chosen for the program" and lists "associating with ethnic minorities" as the fifth characteristic of the eight. Interestingly, the extracurricular activities, which were offered to the boys, included therapeutic football and preparation for entry in the Israeli Defence Force, whereas the girls were offered a course on Judaism, maybe in an attempt to strengthen their Jewish identity, as well as a course on the Israeli legal-judicial system, where they might learn about the legal obstacles that interfaith couples face. Similar programs sprang up in many other local municipalities across the country, and in the media coverage they received, they were presented as clearly aiming to target girls who were having relations with Arab men and teenage Arab boys. ${ }^{11}$

Many other governmental publications make it clear that such interethnic or interfaith relations are seen in a very negative light. Many managers of social work services working with girls at risk confirmed in discussion that associating with minority groups is indeed seen as a risk factor and influences their risk assessment and suggestions for treatment. Conversations with some of the high ranking managers in the services for girls at risk also confirmed that very often girls who have relations with Arab teens or men, and especially when their parents disagree with such relations, are sent to closed institutions for girls in an attempt to dismantle these relationship.

As revealing was the comment made by MK Nissim Ze'ev from Shas during a discussion that took place in the Knesset assembly (January 10, 2012) about "the assimilation trend: Jewish girls living in Arab villages." MK Ze'ev said:

Your honour the minister, our problem is that we want to show that we... can live together with everyone. We need to give kids in year 1 traditional Jewish education. If we don't teach them these things, we will just increase the number of social workers, but will reach nowhere apart from the bottom of the pit.

The tension between holding onto liberal values while attempting to separate Jews and Arabs necessitates employing social workers and psychologists to dismantle the "problematic" unions which occasionally result.

\section{DISCUSSION AND CONCLUSIONS}

The attempts to ban the relations between Arab men and Jewish women are thwarted by the commitment to democratic values and human rights. Forcing Jews to avoid such relations is also likely to be counterproductive and to increase defection. Under these circumstances, the psychological discourse and its related practices appear to offer a solution. It provides "scientific" and "objective" tools for "diagnosing" specific women as having emotional problems. These women require safeguarding, "for their own interest." Being "at risk" justifies "safeguarding," "treatment," and "rehabilitation." This professional psychological discourse and its related practices are not considered to violate democratic principles and therefore transcend controversy and skepticism, while enjoying high credibility (Rose, 1996). It presents itself as making objective truth claims, for the benefit of Jewish women and girls, and so far, it has not been subjected to critical examination. Officially, the freedom of choice is preserved. At the same time, the state has developed a mechanism that allows it to cancel these freedoms in multiple individual cases. This psychological discourse helps also to distract attention from the social marginality imposed on about 300,000 Jewish immigrants, most of them from the former USSR, who were not considered Jewish enough by the Jewish Orthodox courts and therefore are unable to marry other Jews (Sheleg, 2004). Many of these immigrants come from the Islamic republics of the former USSR, including Uzbekistan, Azerbaijan, Kazakhstan and Tajikistan. These immigrants have a strong cultural affinity to the Arab world. In addition, they share social marginality with other Arabs in Israel, which is the background of these inter-faith relations. It is not surprising that the state's social services find it much easier to employ these mechanisms on girls from low socioeconomic groups. These groups are less likely to challenge state's officials and resist. Additional research is desperately 
needed to study these relations and more importantly, to explore the perceptions of social workers and other professionals involved in these interventions.

Israeli social services are usually identified with the liberal left and are often expressing liberal opinions in all other domains regarding sexual, ethnic, or class identity. To explain how they are more likely to reject these interfaith relations, I employed Mary Douglas' $(1992,138)$ model of the enclave and its ways of using "risk" to maintain the social boundaries of the Israeli Jewish enclave.

It seems that the founders of the State of Israel, intending to turn the Jewish people into a nation like all nations, compromised by defining the state as a Jewish ( and democratic) state, thus enhancing the enclave tendencies already so ingrained in Jewish culture. The "outside" and "other men" are still very easily portrayed and seen as a source of great danger or risk which must be protected against. The practices I describe in this article should serve as a cautionary tale regarding the potential misuses of mental health systems to support oppressive, biased, and politically based practices. These can be used not only in cases of mixed marriage, but in any other human behavior that is challenging contemporary local social norms.

\section{NOTES}

${ }^{1}$ Mika Tagpo, a 16-year-old girl from Kiryat Gat was found dead and burnt in the Bedouin town, Rahat. Two young Bedouin men were charged for the murder (Dadon \& Barshkovsky, 2006).

${ }^{2}$ As an example, see pages $32-33$ in the protocol of the emergency discussion about "the kidnapping of immigrant girls by men from national minority groups" that took place in the Knesset Committee for Immigration, Absorption and Diaspora Affairs on December 28, 2011.

${ }^{3}$ The Law of Return is part of Israeli legislation, passed on July 5, 1950. It gives Jews the right of return and the right to live in Israel and to gain citizenship. In 1970, the right of entry and settlement was extended to the people of Jewish ancestry and their spouses. In this category of "being of Jewish Ancestry" are included, in addition to those born as Jews (having a Jewish mother or maternal grandmother), also those having a Jewish father or grandfather "only," and converts to Judaism.

${ }^{4}$ It is interesting to read in comparison with the study conducted by Khatib-Chahidi, Hill, and Paton (1998) on the psychological characteristics of international couples as it uses much more positive terminology. They found that women in international marriages in which the marriage was involved in immigration of one of the partners "were generally more adventurous, free thinking, unconventional, and emotionally stable than the average" (by Khatib-Chahidi et al. 1998, 64).

${ }^{5}$ But how can we explain the fact that in these situations, Arab men are so much more reassuring and supportive then Jewish men? Part of the answer might be found in Hazani's (1989) study of Arab pimps and Jewish prostitutes who are active on "the seam" (areas of interaction between Jews and Arabs) in Israel. Hazani concludes that the Jewish prostitutes are "the active party in the creation and maintenance of the bond between pimp and prostitute" $(1989,67)$ and that they preferred Arab pimps over Jewish pimps. According to Hazani, the social marginality of Arabs in Israel creates a situation in which Arab pimps are much more vulnerable and therefore much less likely to abuse their prostitutes. Added to this is the special respect accorded to the Arab pimp by his friends for having a Jewish girl. As a result of these factors, Arab pimps are considered by Jewish prostitutes to be much more gentle, fair, and respectful comparing to their Jewish equivalent.

${ }^{6}$ In Israel, 14 is the age of consent. Sexual relations under this age are forbidden by law.

${ }^{7}$ Introducing new "educational" measures was explored during a special discussion of the Committee on Women's Rights, which was titled "The Assimilation Phenomena in Israel" and was held on February 8, 2011. Such measures were also considered on December 28, 2011, during a meeting of the Immigration \& Absorption Committee and on May 1, 2012, during a meeting of the Children's Rights Committee. Such interventions were rejected so far.

${ }^{8} \mathrm{~A}$ similar approach is inherent in the Ministry of Religions' response to applications made by Jews who have converted to Islam and ask that their religious affiliation will be changed accordingly in their identity card. Before the change is made, they are invited to an assessment by a psychiatrist and a social worker (Algazi, 2002). 


\begin{abstract}
${ }^{9}$ The official term Mr Atias uses is "Bnei-Miutim," which can be translated as "minority groups."

${ }^{10}$ http://www.shaar.org.il/index.php?page_id = 78 (accessed on March 17, 2015).

${ }^{11} 1$ Another example for such intervention was mentioned during the Committee on Children's Rights (May 19, 2003) that dealt with youth prostitution. The issue comes up as often Arab men are also accused of soliciting Jewish girls to prostitution. Ben Baruch, the police delegate said: "together with the police we have pulled out 80 girls from Bedouin tent camps in the last year. . . all the government ministries were part of it... each girl is monitored individually. A student was attached to each girl. In another project in Hatzerim air-force base, each girl was linked up with one of the women officers. This project is running now for the third time and is very successful. Though the estimates are of around 600 girls we managed to pull out only 80 girls and they are currently under treatment." Further examples can be found in Cohen-Golani $(2011,24)$.
\end{abstract}

\title{
REFERENCES
}

Abu-Rayya, H. M. (2000). Psychological and Sociocultural Adjustment of Intermarried Jews and Arabs in Israel, Unpublished MA dissertation, Hebrew University of Jerusalem, Jerusalem.

Abu-Rayya, H. M. (2007). Acculturation, Christian religiosity, and psychological and marital well-being among the European wives of Arabs in Israel. Mental Health, Religion \& Culture, 10, 171-190. doi:10.1080/ 13694670500504901

Algazi, Y. (2002, December 11) You have converted to Islam: The ministry will send you to a psychiatrist, Ha'aretz. Retrieved March 17, 2015, from http://www.haaretz.co.il/misc/1.846163

Bland, L. (2005). White women and men of colour: Miscegenation fears in Britain after the Great War. Gender \& History, 17(1), 29-61.

Breger, R. A. (1998). Love and the state: Women, mixed marriages and the law in Germany. In R. A. Breger \& R. Hill (Eds.), Cross-cultural marriage: Identity and choice (pp. 129-152). New York: Berg.

Cahan-Stravchinsky, P., Yorovich, L., Konstantinov, V., \& Efrati, R. (2005). Characteristics and needs of the girls treated by the service for girls and young women. Jerusalem: Myers-Joint Brookdale Institute.

Castel, R. (1991). From dangerousness to risk. In G. Burchell, C. Gordon \& P. Miller (Eds.), The Foucault effect: Studies in governmentality (pp. 281-299). Chicago: University of Chicago Press.

Celello, K. (2010). Therapeutic culture and marriage equality what comes naturally and contemporary dialogues about marriage. Frontiers: A Journal of Women Studies, 31(3), 41-48.

Cohen-Golani, S. (2011). “... And I didn't know anything about Arabs at all. . I was new to those things...”: A phenomenological study of the experience of Jewish Girls who engaged in relationships with Arab men. Unpublished MSW dissertation, Ben Gurion University of the Negev, Israel.

Connolly, J. (2009). Forbidden intimacies: Christian-Muslim intermarriage in East Kalimantan, Indonesia. American Ethnologist, 36, 492-506.

Cornwell, G. (1996). George Webb Hardy's The Black Peril and the social meaning of 'Black Peril' in early twentiethcentury South Africa. Journal of Southern African Studies, 22, 441-453.

Dadon, T., \& Barshkovsky, A. (2006, June 23). Charges: Two Bedouin Murdered a Girl and Burnt her Body. Y-Net. Retrieved March 18, 2015, from http://www.ynet.co.il/articles/0,7340,L-3266221,00.html

Das, V. (1995). National honor and practical kinship: Unwanted women and children. In F. D. Ginsburg \& R. Rapp (Eds.), Conceiving the new world order (pp. 212-233). Berkeley: University of California Press.

Douglas, M. (1985). Risk acceptability according to the social sciences. New York: Russell Sage Foundation.

Douglas, M. (1992). Risk and blame: Essays in cultural theory. New York: Routledge.

Foeman, A. K., \& Nance, T. (1999). From miscegenation to multiculturalism: Perceptions and stages of interracial relationship development. Journal of Black Studies, 29, 540-557.

Hakak, Y. (under review). The 'Undesirable Relationships' between Jewish Women and Arab Men: Representation and Discourse in Contemporary Israel.

Hazani, M. (1989). Deviant companionship and interaction across an intergroup "seam": Arab pimps and Jewish prostitutes. Plural Societies, 19, 55-72.

Herdt, G. H. (2009). Moral panics, sex panics: Fear and the fight over sexual rights, intersections: Transdisciplinary perspectives on genders and sexualities. New York: New York University Press.

Hoewe, J., \& Zeldes, G. A. (2012). Overturning anti-miscegenation laws: News media coverage of the Lovings' Legal Case against the State of Virginia. Journal of Black Studies, 43, 427-443.

Kahan-Strawczynski, P., Yurovich, L., Konstantinov, V., \& Efrati, R. 2005. Characteristics and needs of adolescent girls in the care of the service for women and girls of the ministry of social affairs. Jerusalem, (Hebrew): Engelberg Center for Children and Youth, Myers-Joint-Brookdale Institute. 
Keysari, O. (2000). Choosing a partner from a minority group (Bnei-Miutim) among girls at risk as a result of their attachment style and risk taking tendency, Unsubmitted MA dissertation in criminology, Bar-Ilan University, Ramat-Gan.

Khatib-Chahidi, J., Hill, R., \& Paton, R. (1998). Chance, choice and circumstance: A study of women in cross-cultural marriages. In R. Berger \& R. Hill (Eds.), Cross-cultural marriage: Identity and choice (pp. 33-49). Oxford \& New York: Berg.

Ladd-Taylor, M. (2001). Eugenics, sterilisation and modern marriage in the USA: The strange Career of Paul Popenoe. Gender \& History, 13, 298-327.

Lombardo, P. (1987). Miscegenation, eugenics and racism: Historical footnotes to loving v. Virginia. U.C. Davis Law Review, 21, 421-452.

Lopton, D. (1999). Risk. New York: Routledge.

Mai-Ami, N. (2008). Assimilation in Israel and outside of it. Jerusalem: The Knesset Research and Information Centre.

Nahshon-Glick, T., Pliel-Trosman, A., \& Zinger, M. (2007). The Inter-Ministry Plan for the Treatment of Prostitution in Israel, submitted to the inter-ministry committee. Retrieved March 17, 2015, from http://todaango.org.il/wpcontent/uploads/2012/12/142.pdf

Noy-Rozov, T. (2010) Evaluation of the children and families at the centre program. Evaluative Study No. 2. Jerusalem: Tovanot Institute \& The Rashi Foundation.

Pascoe, P. (1996). Miscegenation law, court cases, and ideologies of "race" in twentieth-century America. The Journal of American History, 83(1), 44-69.

Racin, L., \& Dein, S. (2010). Jewish-Arab couple relationships in Israel: underlying motives for entering and engaging in intermarriage. Journal of Muslim Mental Health, 5, 278-300.

Razi, T. (2009). Forsaken children: The Backyard of Mandate Tel-Aviv. Tel-Aviv: Am Oved.

Roer-Strier, D., \& Ben-Ezra, D. (2006). Intermarriages between Western Women and Palestinian Men: Multidirectional adaptation processes. Journal of Marriage and Family, 68(1), 41-55.

Rose, N. (1996). Inventing our selves: Psychology, power and personhood. Cambridge: Cambridge University Press.

Semafumu, S. (1998). Freedom of choice or Pandora's box? Legal pluralism and the regulation of cross-cultural marriages in Uganda. In R. A. Breger \& R. Hill (Eds.), Cross-cultural marriage: Identity and choice (pp. 113-129). Oxford \& New York: Berg.

Sheleg, Y. (2004). Not Halakhically Jewish: The Dilemma of Non-Jewish Immigrants in Israel, policy paper no. 51. Jerusalem: The Israel Democracy Institute.

Shibata, Y. (1998). Crossing racialized boundaries: Intermarriage between "Africans" and "Indians" in contemporary Guyana. In R. A. Breger \& R. Hill (Eds.), Cross-cultural marriage: Identity and choice (pp. 83-100). New York: Berg.

Sohoni, D. (2007). Unsuitable suitors: Anti-miscegenation laws, naturalization laws, and the construction of Asian identities. Law and Society Review, 41(3), 587-618.

Triger, Z. H. (2009). The gendered racial formation: Foreign men, 'our' women, and the law. Women's Rights Law Reporter, 30, 479-525.

Tucker, W. H. (2004). "Inharmoniously adapted to each other": Science and racial crosses. In A. S. Winston (Ed.), Defining difference: Race and racism in the history of psychology (pp. 109-133). Washington, DC, USA: American Psychological Association. 